\title{
Do different time intervals in placement of restorative materials over calcium silicate cements, affect interface microhardness of different restorative materials?
}

\author{
Behnam Bolhari ${ }^{1}$, Naghmeh Meraji ${ }^{2}$, Pegah Khazaee $^{3}$, Sholeh Ghabraei ${ }^{4}$, Sara Valizadeh ${ }^{5}$
}

${ }^{1}$ Associate Professor of Endodontics, Laser Research Center of Dentistry, Dental School, Tehran University of Medical Sciences, Tehran, Iran

${ }^{2}$ Assistant Professor, Department of Endodontics, Dental School, Tehran University of Medical Sciences, Tehran, Iran

${ }^{3}$ Dentist, Tehran University of Medical Sciences, Tehran, Iran

${ }^{4}$ Associate Professor, Department of Endodontics, Dental School/Dental Research Center, Tehran University of Medical Sciences, Tehran, Iran.

${ }^{5}$ Associate Professor, Dental Research Center, Dentistry Research Institute, Restorative Department, Dental School,

Tehran University of Medical Sciences, Tehran, Iran.

\section{Abstract}

Objectives: The type of materials and application time of final restorations on calcium silicate cements (CSCS) are important factors which influence the interfacial properties. The aim of this study was to investigate the effect of different placement time of RMGI (Resin Modified Glass lonomer), composite resin and amalgam over different CSCS on the surface microhardness of these restorative materials.

Methods: Each CSCs material (Biodentine, MTA, CEM cement) was mixed and carried into a hole $(6 \mathrm{~mm}$ diameter $\times 4 \mathrm{~mm}$ thickness) in the center of 270 molds ( $n=90$ /each CSC). Then these molds were randomly divided into three main experimental groups $(n=30)$ in regard of restorative materials (Amalgam, RMGI, Composite) that were placed in the other molds with the same hole size to make restorative materials and CSCs in contact together. Afterwards, each experimental group was divided into three subgroups according to the time interval of restoration placement that was immediately, after $24 \mathrm{~h}$ and after $72 \mathrm{~h}(\mathrm{n}=10)$. Two molds were separated from each other after one week storage in incubator with $100 \%$ humidity in $37^{\circ}$, in order to evaluate the Vickers microhardness of restorative materials in CSC-restorative material interface. Statistical analysis included two-way ANOVA followed by Post hoc Dunnett T3 in cases with lack of homogeneity and Tukey HSD in cases with homogeneity. $(p=0.05)$

Results: The microhardness of all restorative materials was neither significantly influenced by the CSCs materials $(p>0.05)$ nor by the timing of final restoration ( $p>0.05)$ except in RMGI in immediate contact with CEM cement. $(p<0.001)$

Conclusion: Restorative materials hardness in interface with studied CSCs may not affect. This in vitro study found no evidence against immediate definitive restoration over CSCs.
Keywords: Calcium silicate cement; restorative materials; microhardness; time intervals.

Citation: Bolhari B, et al. (2021) Do different time intervals in placement of restorative materials over calcium silicate cements, affect interface microhardness of different restorative materials? Dentistry 3000. doi:10.5195/d3000.2021.159

Received: March, 6, 2021

Accepted: April, 27, 2021

Published: September, 10, 2021

Copyright: (C2021 Bolhari B, et al. This is an open access article licensed under a Creative Commons Attribution Work 4.0 United States License. Email: valizadeh_s@sina.tums.ac.ir 


\section{Introduction}

In recent years, application of biomaterials in dentistry, has resulted in improvement of various restorative and endodontic procedures [1]. Tooth preservation is an ultimate goal in modern dentistry. In this regard, vital pulp therapy (VPT) has gained considerable attention. The aim of VPT is keeping the dental pulp, vital and healthy following carious exposure or traumatic injuries. Some biomaterials can be used as a pulp protective layer in this procedure [2]. Ideally, these materials should be bioactive and biocompatible. Low solubility, ability to bind to dental tissues, adequate setting time and antibacterial activity are some of their characteristics too [3].

CSCs are bioactive materials which are used in many dental treatments like vital pulp therapy, repair of perforations and regenerative treatment. Nevertheless they have many favorable properties, difficult handling and tooth discoloration are considered as their disadvantages [4]. Mineral trioxide aggregate (MTA) was the first CSC introduced in endodontics [5]. Biodentine and Calcium-enriched mixture (CEM) Cement are known as CSCs that are fast setting dentine replacement material and claim to have no discoloration potential respectively [6].

Direct contact of cements with the final restoration happens in most clinical situations. The time span between the CSCs placement and final restoration could have an important role in success rate of treatments [7]. However, it is better to place final coronal restoration immediately after pulp capping to promote coronal seal and less microleakage, this is not possible beacause of long setting time in some CSCs for example MTA [8]. Resin-based composite, glass-ionomer cement (GIC), resinmodified GI (RMGI) and amalgam are common materials that are used for coronal restorations. The effect of immediate coronal restoration on the physical properties of different CSCs has been evaluated in few studies [9, $10,11]$ but based on the authors' search, it is assumed that the effect of the time of coronal restoration on the surface microhardness of restoration has not been assessed. Therefore, the aim of the present study was to investigate the effect of different time placement of RMGI, composite resin and amalgam over different CSCs on the surface microhardness of these restorative materials. It was hypothesized that the microhardness of restorative materials would not be affected by placement time.

\section{Material and Methods}

The materials used in the current study, manufacturer details, their composition and mode of application are shown in Table 1.

Table 1 - Materials composition and mode of application:

\begin{tabular}{|l|l|l|l|}
\hline Material & Manufacture & Composition & Mode of Application \\
\hline Biodentine & $\begin{array}{l}\text { Septodont, Saint Maur- } \\
\text { des-Fosses, France }\end{array}$ & $\begin{array}{l}\text { Powder: Tri-calcium silicate, Di-calcium silicate, } \\
\text { Calcium carbonate and oxide, Iron oxide, zirconium } \\
\text { oxide } \\
\text { Liquid: Calcium chloride, Hydro soluble polymer }\end{array}$ & $\begin{array}{l}\text { One dose of liquid and powder } \\
\text { mixed for } 30 \text { sec at } 4000 \text { rpm in } \\
\text { an amalgamator }\end{array}$ \\
\hline
\end{tabular}




\begin{tabular}{|c|c|c|c|}
\hline CEM Cement & $\begin{array}{l}\text { BioniqueDent, Tehran, } \\
\text { Iran }\end{array}$ & $\begin{array}{l}\text { Powder: Calcium oxide, sulfur trioxide, phosphorous } \\
\text { Pentoxide, silicon dioxide, aluminum trioxide, } \\
\text { sodium oxide, magnesium oxide, chloride } \\
\text { Liquid: Water-based liquid }\end{array}$ & $\begin{array}{l}\text { Mix Powder/Liquid ratio: } \\
3 / 1\end{array}$ \\
\hline ProRoot MTA & $\begin{array}{l}\text { Dentsply Maillefer, } \\
\text { Ballaigues, Switzerland }\end{array}$ & $\begin{array}{l}\text { Powder: Calcium carbonate, silicon dioxide, } \\
\text { aluminum oxide, calcium zirconia complex } \\
\text { Liquid: Distilled Water }\end{array}$ & Mix powder/liquid ratio: $3 / 1$ \\
\hline $\begin{array}{l}\text { AdperTM } \\
\text { Single Bond } 2\end{array}$ & $\begin{array}{l}\text { 3M ESPE, QuadrantLC, } \\
\text { Cavex, Haarlem, } \\
\text { Netherlands }\end{array}$ & $\begin{array}{l}\text { BISGMA, HEMA, dimethacrylates, a methacrylate } \\
\text { functional copolymer of polyacrylic and polyitaconic } \\
\text { acids, ethanol, water, silica fillers, Camphorquinone }\end{array}$ & $\begin{array}{l}\text { 1. Apply } 37 \% \text { phosphoric acid } \\
\text { etchant for } 15 \mathrm{sec} \\
\text { 2. Rinse for } 10 \mathrm{sec} \\
\text { 3. Apply } 2 \text { or } 3 \text { onsecutive coats } \\
\text { of adhesive } \\
\text { 4. Allow gentle air stream for } 5 \\
\text { seconds } \\
\text { 5. Light cure for } 10 \mathrm{sec}\end{array}$ \\
\hline Amalgam & SDI, Victoria, Australia & Amalgam alloy and mercury & In amalgamator \\
\hline $\begin{array}{l}\text { Filtekn } \mathrm{Z250} \\
\text { Composite } \\
\text { resin }\end{array}$ & $\begin{array}{l}\text { 3M ESPE; QuadrantLC, } \\
\text { Cavex, Haarlem, } \\
\text { Netherlands }\end{array}$ & $\begin{array}{l}\text { Filler: } \mathrm{Zr} / \mathrm{Si} \text { ( } 60 \text { vol\%) 0.01-3.5 } \mu \mathrm{m} \\
\text { Resin: BisGMA, UDMA, BisEMA }\end{array}$ & Light cure for $40 \mathrm{~s}$ \\
\hline $\begin{array}{l}\text { Fuji II LC } \\
\text { Light cure glass } \\
\text { ionomer }\end{array}$ & GC, Tokyo, Japan & $\begin{array}{l}\text { Powder: Fluoro-alumino-silicate glass } \\
\text { Liquid: poly-acrylic acid, HEMA, dimethacrylate, } \\
\text { camphorquinone, water }\end{array}$ & Light cure for $40 \mathrm{~s}$ \\
\hline
\end{tabular}

\section{Microhardness test:}

In this in vitro experimental study, 540 cylindrical polymethylmethacrylate molds with a central hole with an internal diameter of $6 \mathrm{~mm}$ and height of 4 $\mathrm{mm}$ (according to ASTM E384 Standard for microhardness tests) were fabricated by CNC laser cutting (LaserProl, GCC, New Taipei City, Taiwan). Half of the molds were considered for CSCs which were placed on slabs and according to the CSC materials randomly divided into three main experimental groups $(n=90)$.

CSC material was prepared according to the manufactures instructions and placed in the molds. Then the rest of the molds were placed on each mold filled with CSC in a way that the two internal holes were positioned along each other. The second mold was used for restorative material placement. Afterwards, each main experimental group was divided into three subgroups $(n=30)$ according to the restorative material applied. The time interval of restoration placement was varied. The final restoration was 
placed a. immediately b. after $24 \mathrm{~h}$ and c. after $72 h(n=10)$.

There was no pretreatment prior to amalgam or glass ionomer placement but before placing composite resin in molds, total etch and bond (AdperTM Single Bond 2) preceded by etching with $37 \%$ phosphoric acid for 15 seconds was applied. Light curing time for both RMGI and composite resin was 40 seconds at 800 $\mathrm{mW} / \mathrm{cm}^{2}$ using a light-emitting diode (Woodipecker, china) light source.

Two molds were separated from each other after one week storage in incubator with $100 \%$ humidity in $37^{\circ} \mathrm{C}$, in order to evaluate the microhardness of restorative materials in CSC and restorative material interface. The side of restorative materials in contact with CSCs were polished using silicon carbide sandpaper with varying particle sizes of 400,500 , $800,1000,1200,1500$ and 2000 grit respectively. All the procedures were done by one person. For the purpose of facilitating indentation and minimizing the influence of sample preparation on surface microhardness, wet polishing with minimal hand pressure was employed. The surface microhardness test was performed using a Vickers Tester (Bareiss Prufgeratebau $\mathrm{GmbH}$,
Oberdischingen, Germany) and a pyramid shaped diamond indenter with a load of $300 \mathrm{~g}$ for $10 \mathrm{~s}$. According to the pilot study this load created a clear and reliable indent in all three materials. Five indents were made on the polished surface of each sample at separate locations with a $2.5 \times$ d (2.5 times the mean diameter of each indent) distance between indentations and each indent from the edge of the sample (in accordance to ASTM E384 standard for Vickers microhardness test). The Vickers microhardness value (HV) was calculated by the testing machine based on the following equation:

$$
\begin{aligned}
& H V=\frac{2 \mathrm{~F} \sin \frac{136^{\circ}}{2}}{\mathrm{~d}^{2}} \\
& H V=1.854 \frac{F}{\mathrm{~d}^{2}}
\end{aligned}
$$

$\mathrm{F}=$ Load in $\mathrm{kgf}$

$\mathrm{d}=$ mean of the two diagonals, $\mathrm{d} 1$ and $\mathrm{d} 2$ in $\mathrm{mm}$

$\mathrm{HV}=$ Vickers microhardness value

\section{Statistical Analysis}

Statistical analysis included twoway ANOVA followed by Post hoc Dunnett T3 in cases with lack of homogeneity and Tukey HSD in cases with homogeneity.

\section{Results}

Mean and standard deviation of Vickers microhardness of different restorative materials in interface with verities of CSCs after several intervals, are listed in table 2.

Amalgam hardness in contact with all of CSCs increased insignificantly $(P$ value $=0.32,0.38$ and 0.25 in contact with Biodentin, CEM cement and MTA respectively) over time. Hardness of composite in interface with different CSCs had no significant changes in different times $(P$ value $=0.11,0.25$ and 0.21 in contact with Biodentin, CEM cement and MTA respectively). RMGI showed significantly decrease in hardness in contact with all of CSCs over time ( $P$ value $=0.001$ ).

Comparison between restorative materials represented that hardness of RMGl is the least among them and amalgam had highest level of hardness contacting with all of CSCs.

There was just one exception, RMGI had greatest hardness in contact with Cem cement immediately. 


\begin{tabular}{|c|c|c|c|c|c|c|c|c|c|}
\hline & \multicolumn{3}{|c|}{ Biodentin } & \multicolumn{3}{|c|}{ Cem cement } & \multicolumn{3}{|c|}{ MTA } \\
\hline $\begin{array}{l}\text { Restorative } \\
\text { Materials }\end{array}$ & immediate & $24 \mathrm{~h}$ & $72 \mathrm{~h}$ & immediate & $24 \mathrm{~h}$ & $72 \mathrm{~h}$ & immediate & $24 \mathrm{~h}$ & $72 \mathrm{~h}$ \\
\hline Amalgam & $\begin{array}{c}186.60 \pm 9.09 \\
a\end{array}$ & $\begin{array}{c}188.86 \pm 17.79 \\
\text { a }\end{array}$ & $\begin{array}{c}199 / 00 \pm 28.63 \\
a\end{array}$ & $\begin{array}{c}144.20 \pm 17.34 \\
a\end{array}$ & $\begin{array}{c}172.46 \pm 5.02 \\
a\end{array}$ & $\begin{array}{c}174.86 \pm 10.87 \\
a\end{array}$ & $\begin{array}{c}153.23 \pm 11.83 \\
a\end{array}$ & $\begin{array}{c}189.76 \pm 18.18 \\
a\end{array}$ & $\begin{array}{c}202.00 \pm 23.61 \\
a\end{array}$ \\
\hline Composite & $\begin{array}{c}136.20 \pm 9.77 \\
b\end{array}$ & $\begin{array}{c}116.13 \pm 13.75 \\
b\end{array}$ & $\begin{array}{c}122.90 \pm 3.01 \\
b\end{array}$ & $\begin{array}{c}123.26 \pm 9.63 \\
b\end{array}$ & $\begin{array}{c}130.76 \pm 2.25 \\
b\end{array}$ & $\begin{array}{c}140.76 \pm 16.89 \\
b\end{array}$ & $\begin{array}{c}127.87 \pm 5.27 \\
\text { b }\end{array}$ & $\begin{array}{c}125.60 \pm 9.18 \\
\text { b }\end{array}$ & $\begin{array}{c}148.57 \pm 23.99 \\
\text { b }\end{array}$ \\
\hline RMGI & $\begin{array}{c}125.90 \pm 6.66 \\
\text { c }\end{array}$ & $\begin{array}{c}97.37 \pm 5.26 \\
d\end{array}$ & $\begin{array}{c}99.00 \pm 28.63 \\
d\end{array}$ & $\begin{array}{c}322.70 \pm 5.73 \\
f\end{array}$ & $\begin{array}{c}111.90 \pm 9.66 \\
d\end{array}$ & $\begin{array}{c}85.23 \pm 9.02 \\
\mathrm{e}\end{array}$ & $\begin{array}{c}118.87 \pm 6.64 \\
c\end{array}$ & $\begin{array}{c}110.43 \pm 6.88 \\
d\end{array}$ & $\begin{array}{c}88.37 \pm 13.39 \\
\text { e }\end{array}$ \\
\hline
\end{tabular}

*Different letters show significant differences between groups

\section{Discussion}

There are some kinds of materials known as calcium silicate cements (CSCs) that recommended for pulp capping process. They provide pulp vitality maintenance and stimulate making growth factors and lead to dentin formation in asymptomatic teeth [12].

Some characteristics are considered for these pulp capping materials like biocompatibility; dimensional stability; insolubility in tissue fluids; easy manipulation; adhesion to the tooth structure; providing adequate seal and remaining in place under dislocating forces [13].

Among different factors affected pulp therapy prognosis, the time of the placement of well-sealed permanent coronal restoration is critical. Glass-ionomer cement (GIC), resin-modified GI (RMGI) Resin-based composite, and amalgam are common materials for coronal restorations [14].

When restorative materials are applied on CSCs immediately or after different intervals, it may that setting reactions of each materials affect the other one setting in the interface between them. Timing of coronal restoration placement on the physical properties of CSCs has been evaluated in some studies $[14,15,16]$ but there is no study about the effect of the coronal restoration placement time on the surface microhardness of restorative materials. Therefore, the aim of the present study was to investigate the microhardness of RMGI, resin composite and amalgam restoration in interface with different CSCs after different time intervals.

Hardness is a property of major importance for assessing the adequate setting of restorative materials [17] It not only represents deformation resistance but also shows stability of material crystalline structure. As there is an inverse relationship between hardness and porosity, adequate levels of hardness play an important role in achieving an ideal seal [18]. Hardness is one of the determinants of the life time of dental materials and prevent restorative material displacement 
and disruption of the physical seal during masticatory occlusal loads [19].

As it is possible to perceive, amalgam hardness in contact with three CSCs used in this study, had an acceptable measure that increased insignificantly with time. This finding showed that amalgam hardness in interface was not affected by the CSCs' hydration process even when immediately placed.

Increasing amalgam hardness over time could be attributed to continuous crystallization of amalgam over time because of the setting reaction rate which is somehow slow and takes several days to be completed [20]. So, it seems that setting conditions of CSCs have no adverse effect on amalgam strength [17]. In contrast some factors like the $\mathrm{pH}$ value of the environment, the condensation pressure, humidity and temperature may affect microhardness of CSCs that it has been studied in many researches [21].

In this study composite reached to optimum microhardness in interface and no adverse effect were seen in composite setting reaction in contact with CSCs and no significant changes in hardness was seen in different placement times. Correlation between the microhardness and the degree of conversion of composite resins have shown in several studies [22] the results of the present study showed that the degree of cross linking in the polymerized matrix reaches the maximum hardness immediately after light curing and it does not change in contact with CSCs setting reaction in different intervals especially in immediate composite placement [23]. In case of immediate coronal restoration, clinical manipulations including the condensation pressure, etching, rinsing, and priming could affect the setting of CSCs [15]

RMGI showed significantly decrease in hardness in contact with all of CSCs over time. The reason may be because of moisture absorption from CSCs by RMGI until microhardness test was done so environment humidity result in water sorption in RMGI. Amalgam and composite are somehow stable materials in presence of humidity, where their water sorption and degradation rate is very low compared with RMGI that present higher degradation and lower hardness values [12]. In a study by Ambrosano it was shown that after RMGl degradation in moisture conditions, the hardness decreased significantly in this material [24]. Comparison between restorative materials represented that hardness of RMGI is the least among them and amalgam had maximum hardness contacting with all CSCs and in all time intervals. This is not unexpected results because of materials mechanical properties as shown in literature that amalgam, composite and RMGI have the highest measure of hardness respectively [25].

There was just one exception in the present study, RMGl had the greatest hardness in contact with Cem cement immediately. In studies by Cantekin and Doozaneh was shown that Cem cement consist of different calcium compounds that can bond chemically with RMGI especially when placed immediately over CEM cement that have not been fully set $[26,27]$. it is supposed during separation of two molds, because of chemical bonding, pieces of CEM cement would remain on the RMGI surface and the higher amount of microhardness was associated with that.

This was an in vitro study; therefore, the condition of the oral cavity wouldn't completely have simulated. In this study just microhardness was evaluated, therefore, it is suggested that other characteristics like microleakage and bond strength between 
different types of restorations and several CSCs, would be studied [28].

It should be noted that in another study, done by the authors, the microhardness of CSCs is evaluated and the results of these both studies will be useful in determination of placement time of restorative materials over CSCs [29].

\section{Conclusion}

Within the limitation of this laboratory study, it was concluded that there is no difference between placement time of restorative materials over studied CSCs in regards of the restorative material microhardness. So immediate placement of a final restoration over CSCs not only provide better coronal seal but also would be clinically beneficial for patients and dentists, decreasing time and cost.

\section{Conflicts of interest}

The authors declare no competing interest.

\section{Availability of data and materials}

The data that support the findings of this research are available from the corresponding author [S.V] upon request.

\section{References}

1. Patel E, Pradeep P, Kumar P, Choonara YE, Pillay V. Oroactive dental biomaterials and their use in endodontic therapy. Journal of Biomedical Materials Research Part B: Applied Biomaterials. 2019 Apr 8.

2. da Rosa WL, Cocco AR, Silva TM, Mesquita LC, Galarca AD, Silva AF, Piva E. C urrent trends and future perspectives of dental pulp capping materials: A systematic review. Journal of Biomedical Materials Research Part B: Applied Biomaterials.

2018 Apr;106(3):1358-68.

3. Zamparini F, Siboni F, Prati C, Taddei P, Gandolfi MG. Properties of calcium silicatemonobasic calcium phosphate materials for endodontics containing tantalum pentoxide and zirconium oxide. Clinical oral investigations. 2019 Jan 29;23(1):445-57.

4. Yazdi KA, Ghabraei $\mathrm{S}$, Bolhari B, Kafili M, Meraji N, Nekoofar MH, Dummer PM. Microstructure and chemical analysis of four calcium silicatebased cements in different environmental conditions. Clinical oral investigations. 2019 Jan 29;23(1):43-52 .

5. Parreira RM, Andrade TL, Luz AP, Pandolfelli VC, Oliveira IR. Calcium aluminate cement-based compositions for biomaterial applications. Ceramics International. $2016 \quad$ Aug 1;42(10):11732-8.

6. Llaquet $M$, Mercadé $M$, Plotino G. Regenerative endodontic procedures: A review of the literature and a case report of an immature central incisor. Giornale italiano di endodonzia. 2017 Nov 1;31(2):65-72.

7. Torabinejad $\mathrm{M}$, Parirokh $\mathrm{M}$, Dummer PM. Mineral trioxide aggregate and other bioactive endodontic cements: an updated overview-part II: other clinical applications and complications. International endodontic journal. 2018 Mar;51(3):284-317.

8. Palma $P$, Marques J, Falacho R, Vinagre A, Santos J, Ramos J. Does Delayed Restoration Improve Shear Bond Strength of Different Restorative Protocols to Calcium Silicate-Based Cements? Materials. 2018 Nov;11(11):2216.

9. Lipski M, Nowicka A, Kot K, Postek-Stefańska L, WysoczańskaJankowicz I, Borkowski L, Andersz P, Jarząbek A, Grocholewicz K, Sobolewska E, Woźniak K. Factors affecting the outcomes of direct pulp capping using Biodentine. Clinical oral investigations. 2018 Jun 1;22(5):2021-9.

10. Ha HT. The effect of the maturation time of calcium silicatebased cement (Biodentine ${ }^{\mathrm{TM}}$ ) on 
resin bonding: an in vitro study. Applied Adhesion Science. 2019 Dec 1;7(1):1.

11. Schmidt A, Schäfer E, Dammaschke T. Shear bond strength of lining materials to calcium silicate cements at different time intervals. J Adhes Dent. 2017 Mar 1;19(2):129-35.

12. Napte BD, Raghavendra SS. Evaluation of shear bond strength of conventional glass ionomer cements bonded to mineral trioxide aggregate: $A n$ in vitro study. Journal of Dental and Allied Sciences. 2015 Jul 1;4(2):73.

13. Bayram HM. Effect of Acidic Environment on Dislodgment Resistance of Different Silicatebased Root Repair Materials. Acta Scientific Dental Sciences. 2018; 2:24-8.

14. Nandini $S$, Ballal $S$,
Kandaswamy D. Influence of glassionomer cement on the interface and setting reaction of mineral trioxide aggregate when used as a furcal repair material using laser Raman spectroscopic analysis. Journal of endodontics. 2007;33(2):167-72.

15. Tsujimoto $M$, Tsujimoto $Y$, Ookubo A, Shiraishi T, Watanabe I, Yamada $S$, et al. Timing for composite resin placement on mineral trioxide aggregate. Journal of endodontics. 2013;39(9):116770.
16. Tunç EŞ, Bayrak Ş, Eğilmez $T$. The evaluation of bond strength of a composite and a compomer to white mineral trioxide aggregate with two different bonding systems. Journal of Endodontics. 2008;34(5):603-5.

17. Caronna V, Himel V, Yu Q, Zhang J-F, Sabey K. Comparison of the surface hardness among 3 materials used in an experimental apexification model under moist and dry environments. Journal of endodontics. 2014;40(7):986-9.

18. Kazemipoor $\mathrm{M}$, Azizi N, Farahat F. Evaluation of microhardness of mineral trioxide aggregate after immediate placement of different coronal restorations: an in vitro study. Journal of dentistry (Tehran, Iran). 2018;15(2):116.

19. Almuslet NA, Elamin $H$, Elbashir B. Hardness enhancement of amalgam teeth fillings using diode laser $(675 \mathrm{~nm})$. Journal of Analytical Science and Technology. 2011;2(2):64-8.

20. Rajih AK, Al-Sultani KF, AlKinani MA. Mechanical properties improvement of dental amalgam using TiO2 and ZnO. Life Sci J. 2015; 12:86-90.

21. Kaur $M$, Singh $H$, Dhillon JS, Batra M, Saini M. MTA versus biodentine: Review of literature with a comparative analysis.
Journal of clinical and diagnostic research: JCDR. 2017;11(8): ZG01. 22. Sahebalam R, Boruziniat A, Mohammadzadeh F, Rangrazi A. Effect of the Time of Salivary Contamination during Light Curing on Degree of Conversion and Microhardness of a Restorative Composite Resin. Biomimetics. 2018;3(3):23.

23. Alzraikat $H$, Taha NA, Qasrawi D, Burrow MF. Shear bond strength of a novel light cured calcium silicate based-cement to resin composite using different adhesive systems. Dental materials journal. 2016;35(6):881-7.

24. AMBROSANO GMB, PUPPIN-RONTANI RM.

Biomechanical degradation of the nano-filled resin-modified glassionomer surface. American Journal of Dentistry. 2012;25(6).

25. Elmi M, Ehsani M, Esmaeili B, Khafri S. Comparison of bond strength of a composite resin with two different adhesive systems and a resin modified glass ionomer to calcium enriched mixture. Journal of conservative dentistry: JCD. 2018;21(4):369.

26. Doozaneh M, Koohpeima F, Firouzmandi $M$, Abbassiyan $F$. Shear bond strength of selfadhering flowable composite and resin-modified glass ionomer to two pulp capping materials. Iranian 


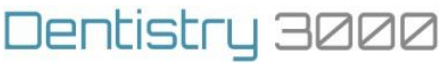

Vol 9 No 1 (2021) DOl 10.5195/d3000.2021.159

endodontic

journal.

2017;12(1):103.

27. CANTEK $\mathrm{N} \mathrm{K}, \mathrm{AVC} \mathrm{S}$. Evaluation of shear bond strength of two resin-based composites and glass ionomer cement to pure tricalcium silicate-based cement (Biodentine ${ }^{\circledR}$ ). Journal of Applied Oral Science. 2014; 22:302-6.

28. Gandolfi M, Spagnuolo G, Siboni $F$, Procino A, Rivieccio $V$, Pelliccioni $G$, et al. Calcium silicate/calcium phosphate biphasic cements for vital pulp therapy: chemical-physical properties and human pulp cells response. Clinical oral investigations. 2015;19(8):207589.

29. Bolhari B, Yazdi KA, Abbasi M, Sanjari S, Meraji N, Özcan M. Calcium silicate cement interface with restorative materials through layering after different time intervals. Odontology.

2021;109(1):210-21. 